\title{
Public Utility Regulation in the U.S. and Asymmetric Return Responses to Positive and Negative Abnormal Earnings*
}

\author{
Emeka T. Nwaeze \\ Rutgers University, U.S.A.
}

This article focuses on regulation and variation in rate structures to investigate asymmetric return responses to positive and negative abnormal earnings. The abnormal earnings (AE) metric is measured as the difference between the actual profit rate and the maximum allowed profit rate, scaled by the beginning-period price. The analysis is motivated by the anticipated asymmetry in the information contents of positive and negative AE induced by existing rate structures which permit utilities to recover below normal profits but allow them to retain abnormal profits. Accordingly, negative AE is expected to be largely transitory and price-irrelevant, whereas positive AE is expected to persist and be price-relevant. The results reveal significant asymmetry in return responses to positive and negative AE. Specifically, the magnitude of return responses is larger for positive than for negative AE. The results further show variations in the magnitudes of price responses across regulatory structures.

Keywords: abnormal earnings, asymmetric return responses, regulatory, structure.

\section{Introduction}

This article focuses on the regulation of public utilities in the U.S. and

*The author acknowledges helpful suggestions by Swaminathan Badrinath, Paul Barnes, Haim Falk, Emel Kahya, Sung Kwon, Teppo Martikainen, Themis Pantos, Eugene Pilotte, Basu Sudipta, and participants at the 1997 4th Annual Conference of the Multinational Finance Society in Greece and at the Rutgers University-Camden workshop. Financial support for this project was provided by the School of Business, Rutgers University-Camden.

(Multinational Finance Journal, 1998, vol. 2, no. 4, pp. 269-293)

CMultinational Finance Society, a nonprofit corporation. All rights reserved.

DOI: $10.17578 / 2-4-2$ 
variations in the regulatory structures to investigate asymmetric return responses to positive and negative abnormal earnings (AE). First, the article describes the asymmetric effects of regulation on the persistence of positive and negative $\mathrm{AE}$ and uses the framework to motivate hypotheses about asymmetric return responses. Second, the article identifies three formal regulation types: (1) Traditional rate-of-return regulation (TRR), which imposes fixed profit rates on firms and regularly adjusts deviations from the fixed rates to match revenues with costs of utility services, (2) incentive regulation (IR) that creates incentives for utilities to achieve short-run cost savings through reductions in operating and fixed expenses, and (3) IR that creates incentives for utilities to obtain long-run cost savings and reductions in capital costs through efficient capacity and investment decisions. The points of departure among the three regulation types are used to motivate hypotheses about cross-sectional variation in return responses to positive and negative AE. ${ }^{1}$ Regulatory climate reflecting the favorableness of cost/profit recovery policies, firm size, and AE size are introduced as control factors to study their mediating effects on return responses to $\mathrm{AE}$.

The analysis focuses on the association between annual returns and AE for at least two reasons. First, in the U.S., the allowed profit rate for a utility is set to equalize the utility's cost of capital. ${ }^{2}$ Hence, profits above or below this rate represent $\mathrm{AE}$ and provide a platform for testing the market effects of abnormal performance in a regulated market. Second, by using AE in lieu of unexpected earnings in the analysis, the design mitigates potential bias in unexpected earnings metric that is often associated with the analysts' earnings-forecasting process. ${ }^{3}$

1. The features used to classify the various regimes into the three, such as limited versus unlimited profit opportunities and incentive for long- versus short-run cost savings, have important implications for earnings persistence that are central to the hypotheses tested in this article.

2. The law requiring utility profits to equalize the investors' required yield began with two landmark cases: the 1923 Bluefield Water Works and Improvement Company v. Public Service Commission of the State of West Virginia (262 U.S. 679) and the 1944 Federal Power Commission v. Hope Natural Gas Company (320 U.S. 591). In both cases, the courts ruled that a utility should charge a rate that is adequate to maintain its credit and capital and provide returns commensurate with returns on investments having similar risks.

3. The use of AE to study returns-earnings relation has several desirable features. First, $\mathrm{AE}$ summarizes firm performances for the entire year rather than for a short event-period, 
The results show that the return effects of positive and negative AE are asymmetric. Positive AE have larger absolute return effects than negative $\mathrm{AE}$. There is also a marked variation in return responses to $\mathrm{AE}$ across regulation types. Specifically, the effect of AE on returns is more favorable for IR than for TRR utilities. The results further show that the effects of positive $\mathrm{AE}$ on returns are larger and more favorable for utilities subject to IRs that address long-run cost-savings and reductions in capital costs than for utilities subject to IRs that focus on short-term cost savings. Moreover, regulatory climate has a positive effect on the association between returns and AE. Utility size has a positive effect on the returns-AE relation for utilities whose IRs focus on short-term cost savings, but has a negative effect on the returns-AE relation for other utilities.

The rest of the article proceeds as follows: Section II surveys the literature on asymmetric return responses to earnings news. Section III develops the hypotheses about return responses to $\mathrm{AE}$ for electric utilities. Section IV describes the empirical methods. Section V presents the results. Section VI summarizes the findings.

\section{Literature Review}

Several studies suggest that positive and negative earnings news possess different valuation properties. Basu (1995), for example, suggests that accounting conservatism creates asymmetric information content for losses and profits by requiring early recognition of current and future probable losses but no recognition of future probable gains. The asymmetry in timing the recognition of losses and profits, in turn, gives rise to asymmetric return responses. Hayn (1995) argues that losses represent an extreme earnings situation that is not expected to persist, else investors will liquidate the firm. Thus, losses for going-concern firms have little relevance for security valuation. It has also been argued that, compared to gains, losses are dominated by nonrecurring items that

providing a broader index of performance improvements. Second, the index does not rely on unobservable market expectation to validate the returns-earnings relation. This latter point is of particularly importance because the extant evidence which shows that results obtained from unexpected returns-unexpected earnings designs are sensitive to the choice of earnings expectation models (e.g., Philbrick and Ricks [1991]). 
do not reliably portend future economic prospects for firms. As a result, investors tend to ignore such information and resort to alternative information sources for security valuation (Brooks and Buckmaster [1976]; Elgers and Lo [1994]).

Numerous studies also demonstrate asymmetric earnings response coefficient (ERC) for small and large values of unexpected earnings (e.g., Freeman and Tse [1992]; Cheng et al. [1992]; Das and Lev [1994]; Subramanyam [1996]). Freeman and Tse argue that extreme values of unexpected earnings contain proportionately large transitory items that depress the ERC. Subramanyam (1996) examines a setting in which signal precision is random and exogenous. His analysis shows that the marginal price response is decreasing in the absolute value of unexpected earnings. He contends that the market associates more noise (lower precision) with extreme news, resulting in lower average price response per unit of extreme unexpected earnings. Penno (1996) assumes an endogenous precision choice and analyzes price responses to good and bad signals. He derives an equilibrium reporting strategy under which managers choose high (low) precision for bad (good) news. The analytic results portend a pricing function that is asymmetric for good and bad news. Elsharkawy and Garrod (1996) report differential price responses to positive and negative annual earnings changes conditional on investor sophistication. These studies suggest patterns of price responses that are asymmetric for positive and negative earnings signals.

\section{Regulation and Asymmetric Return Responses to Positive and Negative Abnormal Earnings}

Rate regulation in the U.S. involves a cost-plus pricing regime in which regulators set the required revenues for a utility to cover operating costs plus a maximum allowed profit rate (MPR) on book value. The required revenues are divided by the projected electricity sales to obtain the allowed customer rate, simply known as the rate. In principle, the MPR should correspond to the investors' required yield. Typically, regulators use a conventional measure of cost of capital (e.g., a firm's weighted average cost of capital) to derive an MPR that reasonably approximates the required yield. The rate is to be revised routinely in response to 
changes in costs and demand to ensure that the actual profit rate (APR) is consistent with the MPR and to eliminate wealth transfers between owners and ratepayers. If the process is applied strictly, then departures of APR from MPR will be transitory and will have limited effects on returns.

\section{A. Departure from Cost-Plus Pricing and the Return Effect of Positive Abnormal Earnings}

In practice, existing rate structures depart from pure cost-plus pricing; adjustments of rates to cost and demand shocks are neither continuous nor instantaneous. Typically, there are regulatory lags in adjusting rates to changes in costs and demand. Such lags average nine months, e.g., Abdel-khalik (1988) and Bryan and Hwang (1997). The lags occur due to practical and policy reasons. For example, review of rate cases involves lengthy testimonies by utilities and interveners that last for months/years. Since the utility rates must remain at the previous level during the review, the disparity between revenues and costs also remains for the duration of the review, distorting the cost-plus process. ${ }^{4}$ Furthermore, regulators often use the lags as a policy tool to motivate efficient production. ${ }^{5}$ They allow utilities to retain positive AE obtained through cost-cutting efforts during the lag periods (Joskow and Schmalensee [1986]).

More generally, regulators rarely reduce rates when actual profits exceed the allowed target. Rather, utilities are allowed to retain excess profits if they can do so without raising rates (Joskow [1973]; Stober [1988]; Lanen [1996]). ${ }^{6}$ Nwaeze (1997a) finds that above-average return on equity for utilities, in fact, persists for several periods and opines that the result may reflect certain strategies employed by utilities

4. Regulators occasionally grant an interim rate relief to a utility during the hearing phase if the existing shock to revenues and costs poses a significant threat to the liquidity of the enterprise.

5. Several studies advocate the use of regulatory lags as an incentive device (e.g., Baumol [1968]; Bailey and Coleman [1971]). The argument is that if the utility rate is fixed for several periods, a utility will be motivated to reduce costs and capture extra profits during the regulatory lag.

6. A survey of recent annual reports of utilities also reveals that pending rate cases consist largely of petitions filed by utilities and only a few cases initiated by regulators. 
to retain rather than refund positive $\mathrm{AE} .{ }^{7}$ Carleton (1974) shows that $\mathrm{AE}$ retained by a utility, even for a period, lead to a lasting change in cash flows. Joskow and McAvoy (1975) also show that retained AE have cash-flow effects. The retained AE produce cash flows in the form of (1) interest on equity capital, (2) base cost recovery, and (3) a profit component.

The preceding discussions suggest that the actions of both the regulators and utilities facilitate the persistence of positive AE. This motivates the hypothesis that:

Hypothesis 1: Positive abnormal earnings have a significant effect on returns for electric utilities. ${ }^{8}$

\section{B. Regulatory Constraints and the Return Effects of Negative AE}

Whereas regulators enforce the profit ceiling loosely for positive AE, they create cost-recovery structures that render negative AE largely transitory. Under current practice, utilities are permitted to defer and subsequently recover abnormal declines in profits caused by unforeseen events. Utilities have typically exploited this guideline to recover costs associated with sudden increases in input prices, accidental impairment of assets, power outages, decline in demand, etc. Another aspect of regulation that affects the economics of negative $\mathrm{AE}$ is the automatic fuel adjustment clause (FAC). FAC allows a utility to adjust rates automatically to offset earnings attrition caused by sudden increases in fuel costs. For example, under FAC, if purchased fuel costs exceed the forecasted price, the extra costs are deferred and included in future

7. Utilities are believed to overwhelm regulators with petitions, perhaps to distract from outcomes that violate regulatory orders and thus increase regulatory lags. Utilities are also suspected to preemptively file complaints with the courts and to carry out vigorous publicity campaigns to sway public opinion and mitigate potential litigation by consumer groups. While utilities are suspected to employ these strategies, empirical verification is difficult because managers are unlikely to disclose any strategies that appear to circumvent the rate process.

8. While Hypothesis 1 appears to be intuitive and supported by empirical evidence for unregulated firms, it implies a departure from the cost-plus pricing structure that is designed to align utility revenues with the cost of providing services. If the cost-plus pricing works as designed, then abnormal profits will be largely transitory and will have little implication for returns. 
rates. ${ }^{9}$ The goal is to allow utilities to promptly mitigate the profit effects and risk associated with shocks to fuel costs.

The Accounting Principles Board (APB 1962, Para. 2 and 3) approved departures from GAAP that are pursuant to regulatory orders that allow utilities to defer costs/expenses that would ordinarily be charged against current income but which will be included in future revenues. ${ }^{10}$ Large increases in such deferrals began in the 1970s, primarily due to the oil crisis of the 1970s. ${ }^{11}$ In response, the FASB promulgated FAS 71 (FASB 1982) to promote a consistent reporting of the economic effects of such deferrals. The standard establishes the guidelines for utilities to capitalize and amortize such deferred costs (see FAS 71, para. 9). ${ }^{12}$

The various cost-recovery regimes suggest that utilities have opportunities to recover all or a portion of abnormal declines in profits. ${ }^{13}$ Accordingly, negative AE, unlike positive AE, will have little

9. Regulators often set limits on the rate increases that firms can make in a given period. Fuel purchases are also reviewed routinely to ensure that utilities follow prudent cost-recovery practices.

10. A part of the Addendum reads, "For example, if a cost incurred by a regulated business during a given period is treated for rate-making purposes by the regulatory authority having jurisdiction as applicable to future revenues, it may be deferred in the balance sheet at the end of the current period and written off in the future period or periods in which the related revenues accrue, even though the cost is of a kind which in a unregulated business would be written off currently."

11. Until the 1970s, such deferrals were relatively small, largely because the 1950s and 1960s were characterized by stable factor prices and low interest rates that, in turn, allowed utilities to capture adequate profits at low rates (Joskow [1974]). The absence of large deferrals during the 1960s perhaps explains the little attention given to the accounting treatment of such deferrals in APB Opinion 2. Loudder et al. (1996) note also that the magnitude of such deferrals before the mid-1970s was small and was of little concern to the Financial Accounting Standards Board (FASB).

12. In recognition of the progressive deregulation of the electric utility industry, FASB promulgated FAS 101 (FASB [1988]) and FAS 121 (FASB [1995]), modifying the original provisions of FAS 71 to recognize those aspects that have material adverse effects on the recovery of regulatory assets. Specifically, both standards require utilities to write off regulatory assets capitalized under FAS 71 if an existing condition, such as deregulation, renders recovery of such assets improbable.

13. FACs have become an important component of the rate process. For example, by $1974,65 \%$ of larger investor-owned utilities had FACs in their residential schedules, $77 \%$ had FACs in their commercial schedules, and 83\% had FACs in their industrial schedules (Baron 
effect on a utility's net cash flows and may thus be largely priceirrelevant. This view of the cost/profit recovery process motivates the hypothesis that:

Hypothesis 2: For electric utilities, negative abnormal earnings have no significant effects on returns and hence have smaller response coefficient than positive abnormal earnings.

\section{Variation in Rate Structures and Differences in Return Responses to Abnormal Profits}

To assess the effect of regulation type on returns-AE relation, firms are classified into three regulatory structures based on the assessed effect of the regulation type on the persistence of AE. ${ }^{14}$ The regulation types and their potential effects on the return-AE relation are discussed next.

\section{Type-I Regulation: Traditional Rate-of-Return Regulation.}

Under the traditional rate-of-return regulation, regulators establish a required revenue level for a utility and routinely revise the required level to ensure that the MPR at the beginning of each period is commensurate with the investors' required yield. While such a constraint is applied loosely, firms under the traditional regime have no formal authorization to retain excess profits. Regulators in such jurisdictions are also apt to limit the size of deviation of APR from MPR that will be allowed to persist. Utilities under such regimes may also refund positive $\mathrm{AE}$ voluntarily to avert future adverse regulation. ${ }^{15}$

and De Bondt [1981]). According to the Congressional Research survey (U.S. Senate, 1977), rate increases resulting from the application of FACs in various states from 1973 to 1976 are $\$ 1$ billion, $\$ 2.6$ billion, $\$ 6.4$ billion, and $\$ 5.2$ billion, respectively. These rate increases represent cost pass-throughs that would ordinarily be charged to income for unregulated firms but against which utilities were sheltered.

14. It has been shown that variation in rate structures differently affects performance across utilities. Nwaeze (1997a), for example, finds that changes in ROE persist longer for IR than for TRR utilities. Nwaeze (1997b) also finds that the association between returns and investments are different for different IRs. Hagerman and Ratchford (1974), Archer (1981), Norton (1985), Rao and Moyer (1994), also show that regulatory climate is related to economic prospects of utilities.

15. Utilities are believed to strategically adopt profit-reducing actions just before rate reviews to relax future regulatory constraints (Sappington [1980]; Sherman [1989]). 
Thus, for the traditional rate-of-return firms, positive AE may have limited effects on future cash flows.

\section{E. Incentive Regulation: The General Structure.}

Incentive regulation (IR) is a modification of the traditional system designed to respond to rising utility costs and to public sentiments against the traditional rate system. ${ }^{16}$ Incentive regulation simulates competitive-type operations by providing economic rewards for efficient use of resources and penalties for inefficiency. Typically, an incentive program allows a firm to keep all or a portion of excess profits that result from efficiency gains but also forces the firm to absorb the costs that result from inefficiency. ${ }^{17}$ Efficiency/inefficiency is judged by comparing actual outputs with set output levels. If a firm's performance exceeds the target, then the firm keeps or shares the cost savings. ${ }^{18}$ Performances that fall below a certain threshold automatically trigger a review of the entire program, usually to allow the utility to recover the abnormal costs.

\section{F. Type-II Regulation: Incentive Regulation for Short-run Cost Savings.}

Type-II regulation addresses short-term performances, such as fuel cost indexing, management performance, energy conservation, and fixed costs. Fuel cost indexing attempts to control operating costs and to generate short-run cost savings through efficient fuel purchase and use.

16. The widespread use of IRs began with the oil crises of the 1970s. The growth in oil prices in the 1970s forced regulators to grant rate increases to bring revenues in line with production costs. Consumers, however, opposed the rate hikes, demanding that utilities should bear the costs of bad decisions (Manzi [1986]; Smarrt [1986]). Public sentiment also grew against the traditional rate system. Many states responded by adopting IRs to motivate higher productivity at lower costs.

17. Because of the difficulty associated with proving inefficiency, penalties for inefficiency are rare and are used only for exceptionally bad decisions (see, e.g., Joskow and Schmalensee [1986]).

18. As shown latter, IRs vary in structure across firms. For example, out of the 75 programs surveyed by Landon (1990), 62\% address power plant performance, $19 \%$ address fuel and purchased power costs, $5 \%$ address fixed plant costs, and $14 \%$ focus on a variety of issues, including management performance. In every case, however, performance above a designated target is rewarded with a certain percentage of the resultant cost savings. 
Under this system, forecasted fuel costs are included in the rate base. The difference between projected and actual costs is shared between utilities and ratepayers. Such programs are often supplemented with heat rate targets to motivate production of power from efficient facilities. Heat rate is the quantity of the British thermal units of energy per kilowatt-hour of electricity. Efficient generation of electricity lowers both the heat rate and fuel costs.

Incentive regulation on management efficiency attempts to control operating costs through a variety of management-performance targets. Targets may include target expense and profit ratios. Such programs allow managers to pursue cost savings through a variety of operating decisions. An incentive program on energy conservation/demand-side management allows utilities to recover all or a portion of expenditures on energy conservation and demand-side management. Incentive regulation on fixed costs attempts to reduce fixed costs through costcontainment incentives. Typically, regulators and utility managers jointly adopt cost estimates for designated projects. Following this, the utility keeps (absorbs) a portion of the cost savings (overruns) resulting from activities on the projects.

A potential issue for firms subject to these incentive types is that improvements that can be achieved through operating decisions are finite and likely to decline over extended periods. For example, the cost savings from fuel-cost indexing will ratchet down or become progressively smaller as the potential for additional efficiency gain (through further reductions in fuel costs) declines. In some cases, utilities are forced into long-term power supply contracts, which obligate them to purchase power from designated sources at contracted prices. Such contracts limit the amount of cost savings that can be achieved through fuel purchases. Similarly, performance improvements through expense reduction, demand side management, or fixed-cost cutting are finite, and are likely to diminish over extended periods.

\section{G. Type-III Regulation: Incentive Regulation on Long-run Performance Improvement.}

Type-III incentive programs focus on long-run reductions in capital costs through sustained improvements in capacity management. The programs address generating plant performance, focusing on two output indicators: capacity factor (i.e., the maximum generation capacity 
provided) and equivalent availability factor (i.e., the degree to which a generating unit is actually available for production in a given period). These programs typically establish target capacity factors; if performance exceeds (falls below) the target in any given period, utilities keep (absorb) a set percentage of the cost savings (costoverruns). Under such programs, improvements in capacity factors often trigger reductions in purchased power, heat rate, and fuel costs. Penalties for poor performance under such programs are infrequent because the boundary below which performances are judged poor is, in most cases, low.

\section{H. The Implications of the Various Regulation Types for the Return-AE Relation}

Given the cost/profit recovery structures under the IR and TRR programs, it is predicted that (1) positive AE will persist longer for IR (type-II and type-III) utilities than for TRR (type-I) utilities, (2) the recovery prospects for negative $\mathrm{AE}$ are better for IR (type-II and typeIII) than for TRR (type-I) utilities, and (3) positive AE will persist longer for type-III utilities than for type-II utilities. Following the extant evidence that ERC is increasing in earnings persistence, the preceding discussions motivate the following hypotheses:

Hypothesis 3: The return response to abnormal earnings is more favorable for IR and TRR utilities

Hypothesis 4: The return response to abnormal earnings is more favorable for type-III than for type-II utilities

\section{The Mediating Effects of Regulatory Climate and Utility Size}

The climate in which a utility operates can have an impact on its performance. Regulatory climate describes regulators' responses to regulatory factors that affect utility performance, including the speed with which regulators respond to unexpected adverse conditions, the ease with which they allow costs into the rate base, their tendency to grant more or less rate than requested, etc. Several studies have shown that rankings of regulators based on such factors are related to firm performance (Archer [1981]; Rao and Moyer [1994]; Khurana and Loudder [1994]; Loudder et al. [1996]). As a result, the ability of a 
utility to retain positive $\mathrm{AE}$ or recover negative $\mathrm{AE}$ may be affected by such regulatory factors.

Several studies have also examined firm factors that affect risks and returns for utilities. The major conclusion is that the impact of firm factors on risks and returns for utilities depends largely on how those factors interact with regulation (Clarke [1980]; Norton [1985]). Hagerman and Ratchford (1978), for example, consider the effect of firm size on regulated rates. They contend that large utilities have the expertise and resources to extract better cost-recovery decisions from regulators and to undertake more efficient investments (see also Abdelkhalik [1988]). Hence, besides proxying for risk, firm size may be positively related to cost-recovery prospects and to the ability of utilities to earn and sustain positive changes in profits. ${ }^{19}$

\section{Empirical Methods}

\section{A. The Data and Sample Selection}

A list of 75 utilities subject to incentive regulation between 1976 and 1995 are collected from Edison Electric Institute (1987) and Landon (1990) reports. The list consists of every utility that operates as a single or holding company subject to incentive regulation. The list is further screened to include only those utilities that are still under the incentive programs at the end of 1995 and derive at least $80 \%$ of their revenues from the state that imposed the incentive programs. ${ }^{20}$ These criteria resulted in 35 incentive-regulation firms, comprising 19 type-II and 16 type-III firms. Next, 39 utilities are identified as type-I utilities (i.e., utilities that have never been subject to incentive regulation in the test period). From this sample, 19 utilities are randomly selected to match

19. Several studies show an inverse relation between firm size and expected returns (e.g., Banz [1981]; Reinganum [1981]; Atiase [1985]; Freeman [1987]). The explanation for the inverse relation is that large firms are more diversified, more stable, and less risky than small firms. Hence, they have lower expected returns.

20. A firm was eliminated if (1) the IR offered no rewards for superior performance but imposed a penalty for poor performance and (2) the firm is in the process of liquidation or has merged with another firm during the sample period. These criteria were imposed to mitigate confounding effects of factors that are unrelated to incentive regulation or traditional rate-ofreturn. 
the sample size for type-II utilities. Data for all of the utilities are obtained from the Compustat and from Moody's Public Utility Manuals from 1976 to 1995 . The data include book value per share (B), earnings per share available to common shareholders (EPS), and fiscal year-end closing prices. Data for MPR and regulatory climate ratings of aboveaverage, average, and below-average are obtained from the Value Line Investment Survey.

The security return, $R_{i, t}$, and abnormal earnings, $A E_{i, t}$, are computed as follows: ${ }^{21}$

$$
R_{i, t}=\left(\frac{P_{i, t}-P_{i, t-1}}{P_{i, t-1}}\right),
$$

where $P_{i, t}$ is the fiscal year-end closing price for security $i$, and:

$$
A E_{i, t}=B_{i, t} \times\left(\frac{A P R_{i, t}-M P R_{i, t}}{P_{i, t-1}}\right) .
$$

The $A P R_{t}=E P S_{t} / B_{t}$, where EPS and $\mathrm{B}$ are as defined earlier. ${ }^{22}$ The AE is scaled by the beginning-period price as in prior studies to be consistent with the return in equation 1 .

\section{B. Empirical Model}

To investigate the effects of regulation type on the return-AE relation, the utilities are grouped by the regulation type (i.e., type-I, type-II, or type-III). A regression model is estimated for utilities in each group as:

21. Security return computed as $\log \left(P_{t} / P_{t-1}\right)$ was also used in the analysis and the results are qualitatively similar to the ones based on the equation in the text and are omitted for brevity. Moreover, Beaver, Lambert, and Ryan (1987) show that response coefficients are virtually the same whether return is defined as the change in price inclusive or exclusive of dividends scaled by beginning-period price or as market model prediction error.

22. If a utility operates in two or more states that grant different rates of return, the $M P R$ is obtained by weighting the separate rates by the total sales from each state. Also, as an alternative to $A P R$ reported by Value Line, $A P R$ was estimated with operating income and the results are qualitatively the same as those based on Value Line reports. 


$$
\begin{aligned}
R_{i, t}=\alpha_{0, i}+ & \gamma_{1, i} A E_{i, t}+\gamma_{2, i}\left(D_{t} \times A E_{i, t}\right)+\gamma_{3, i}\left(C L M_{t} \times A E_{i, t}\right) \\
& +\gamma_{4, i}\left(S Z \times A E_{i, t}\right)+\gamma_{5, i}\left(A E_{i, t}^{2}\right)+e_{i, t}
\end{aligned}
$$

$R_{i, t} \quad=$ Return for utility $i$ in year $t$.

$A E_{i, t}=$ Abnormal earnings for the utility in year $\mathrm{t}$.

$D_{t} \quad=1$ if $\mathrm{AE}$ for the utility in year $\mathrm{t}$ is negative and 0 otherwise.

$C L M_{t}=1$ if the utility is in a favorable climate in year $\mathrm{t}$ and 0 otherwise.

$S Z=1$ if the size of the utility is above the median size for all the utilities and 0 otherwise.

The $\alpha_{0}$ is the intercept; $\gamma_{1, i}$ measures price response to positive AE for a firm under regulation type $i$, controlling for the climate in which the firm operates, the size of the firm, and the absolute magnitude of AE; $\gamma_{2, i}$ is the marginal effect of negative AE on the return for the firm; $\gamma_{3, i}$ measures the mediating effect of regulatory climate on the returns-AE relation for the firm; $\gamma_{4, i}$ measures the mediating effect of utility size on the returns-AE relation for the firm; $\gamma_{5, i}$ is the mediating effect of the absolute size of $\mathrm{AE}$ on returns-AE relation.

\section{Empirical Results}

\section{A. Descriptive Statistics}

Table 1 presents the descriptive statistics for the variables. The $t$-value that MPR is higher for type-I utilities than for type-II and type-III utilities is 9.80 and 14.99 , respectively. This supports the view that strict regulators grant higher MPR, perhaps, to compensate for the restrictive cost-recovery policy. Type-I utilities have the highest risk and returns, followed by type-II utilities. Type-III utilities have the lowest returns. The low return levels for type-II and type-III utilities may also reflect the possibility that IR programs, in general, reduce regulatory risk by relaxing the constraints on profits and providing greater opportunities for firms to capture and permanently retain abnormal profits.

\section{B. Regression Results and Test of Hypothesis 1 and Hypothesis 2}

Initially, a pooled time-series cross-sectional regression is applied to 
TABLE 1. Descriptive statistics of variables

\begin{tabular}{|c|c|c|c|c|c|c|}
\hline & $\begin{array}{r}\text { Type- } \\
n\end{array}$ & $\begin{array}{l}\text { utilities, } \\
=276\end{array}$ & $\begin{array}{r}\text { Type-I } \\
,\end{array}$ & $\begin{array}{l}\text { atilities, } \\
250\end{array}$ & Type-I & $\begin{array}{l}\text { utilities, } \\
=219\end{array}$ \\
\hline & Mean & Med & Mean & Med & Mean & Med \\
\hline$R$ & $\begin{array}{l}.068 \\
(.23)\end{array}$ & .06 & $\begin{array}{l}.05 \\
(.18)\end{array}$ & .053 & $\begin{array}{l}.042 \\
(.11)\end{array}$ & .043 \\
\hline$A P R$ & $\begin{array}{l}12.29 \\
(2.59)\end{array}$ & 12 & $\begin{array}{l}11.92 \\
(2.62)\end{array}$ & 12.1 & $\begin{array}{l}11.340 \\
(1.79)\end{array}$ & 11.5 \\
\hline$M P R$ & $\begin{array}{c}14.32 \\
(1.5)\end{array}$ & 13.7 & $\begin{array}{l}13.39 \\
(1.33)\end{array}$ & 13 & $\begin{array}{l}12.8 \\
(1.19)\end{array}$ & 12.75 \\
\hline$A E$ & $\begin{array}{l}-.01 \\
(.038)\end{array}$ & -.009 & $\begin{array}{c}-.015 \\
(.02)\end{array}$ & -.013 & $\begin{array}{c}-.015 \\
(.02)\end{array}$ & -.015 \\
\hline Beta & $\begin{array}{l}.85 \\
(.1)\end{array}$ & .81 & $\begin{array}{c}.69 \\
(.07)\end{array}$ & .7 & $\begin{array}{l}.6 \\
(.1)\end{array}$ & .63 \\
\hline$t(\overline{M P I}$ & $\overline{M P R_{2}}$ & $9.80 * * *$ & & & & \\
\hline$t(\bar{M}$ & - & $4.99 * * *$ & & & & \\
\hline
\end{tabular}

Note: $R_{t}=$ annual return $=\left(P_{t}-P_{t-1}\right) / P_{t-1}$, where $P_{t}$ is the fiscal year-end closing price adjusted for stock splits; Beta $=$ market-model systematic risk; $A P R=$ actual profit rate; $M P R$ $=$ maximum allowed profit rate; $A E_{t}=B_{t}-\left(A P R_{t}-M P R_{t}\right) / P_{t-1}$, where $B_{t}$ is the book value per share and $A P R$ and $A P R$ are the actual and maximum allowed rates of return, respectively. $n$ $=$ number of observations; standard deviations are in parentheses The $t$-value $=\left(\overline{M P R_{1}}-\overline{M P R_{2}}\right) /\left\{\left[\left(\left(n_{1}-1\right) \mathrm{v}_{1}+\left(n_{2}-1\right) v_{2}\right) /\left(n_{1}+n_{2}-2\right)\right]\left(1 / n_{1}+1 / n_{2}\right)\right\}^{1 / 2}$, where $v_{1}$ and $v_{2}$ are the variances of $\overline{M P R_{1}}$ and $\overline{M P R_{2}}$, respectively and $n_{1}$ and $n_{2}$ are the number of observations for Type-I and Type-II utilities, respectively.***Significant at 0.0001 probability.

obtain benchmark estimates of the coefficients. The results are shown in table 2.

The coefficient for positive AE, $\gamma_{1}$, is positive and significant $(P$ $<.024)$, consistent with hypothesis 1 that positive AE have significant effect on returns. This result corresponds to a scenario in which profits above the maximum allowed profit rate are assessed to have positive impact on future cash flows. Notice, however, that the marginal effect of negative $\mathrm{AE}$ on returns, $\gamma_{2}$, is negative and significant $(P<.05)$. The slope coefficient for negative $\mathrm{AE},\left(\gamma_{1, i}+\gamma_{2}\right)$, after controlling for regulatory climate, firm size, and size of $\mathrm{AE}$, is .349 and is smaller in magnitude than the coefficient of 1.301 for positive AE. These preliminary results indicate that the effect of negative $\mathrm{AE}$ on returns is 
TABLE 2. Pooled Cross-Sectional Regression of Price Responses to Positive and Negative Abnormal Profits for Electric Utilities

\begin{tabular}{|c|c|c|c|}
\hline \multicolumn{4}{|c|}{$R_{i}=\alpha_{0}+\gamma_{1} A E_{i}+\gamma_{2}\left(D \times A E_{i}\right)+\gamma_{3}\left(C L M \times A E_{i}\right)$} \\
\hline \multicolumn{4}{|c|}{$+\gamma_{4}\left(S Z \times A E_{i}\right)+\gamma_{5}\left(A E_{i}^{2}\right)+e_{i}$} \\
\hline & Estimate & $t$-value & $\mathrm{P}>|\mathrm{T}|$ \\
\hline$\alpha_{0}$ & .096 & $(2.11)$ & .018 \\
\hline$\gamma_{1}$ & 1.301 & $(1.98)$ & .024 \\
\hline$\gamma_{2}$ & -.952 & $(-1.67)$ & .048 \\
\hline$\gamma_{3}$ & 645 & $(1.78)$ & .038 \\
\hline$\gamma_{4}$ & -1.369 & $(-1.26)$ & .104 \\
\hline$\gamma_{5}$ & -1.653 & $(-3.2)$ & .001 \\
\hline$R^{2}$ & & .118 & \\
\hline No. of observations & & 745 & \\
\hline
\end{tabular}

Note: $R=\left(P_{t}-P_{t-1}\right) / P_{t-1}$, is annual return, where $P_{t}$ is the fiscal year-end closing price adjusted for stock splits; $A E_{t}=B_{t} \times A E_{t}=B_{t} \times\left(A P R_{t}-M P R_{t}\right) / P_{t-1}$; where $B_{t}$ is the book value per share and $A P R$ and $M P R$ are the actual and maximum allowed rates of return, respectively; $D=$ profit indicator that is 1 if $A P R>M P R$ and 0 otherwise; $C L M=$ climate indicator that is 1 if a firm is in a favorable regulatory climate and 0 otherwise; and $S Z=$ size indicator that is 1 if firm size is greater than the median size for all utilities in the sample and 0 otherwise.

muted and provide support for hypothesis 2 that negative $\mathrm{AE}$ have smaller effects on return than positive AE.

Regulatory climate has a positive (albeit marginally significant) effect on the association between returns and AE. This result is consistent with the view that favorable climate is positively related to the ability of utilities to earn and sustain positive changes in profits. Utility size, on the other hand, has a negative but insignificant effect on the association between returns and abnormal earnings. This result fails to support the view that large utilities have superior skills compared to small utilities in extracting favorable rate decisions and sustaining positive $\mathrm{AE}$. Notice also that the coefficient on $\mathrm{AE}^{2}$ is negative and significant, consistent with the notion that return responses to earnings news are decreasing in the absolute size of the earnings news (see, Subramanyam [1996]).

To investigate a potential variation in the return responses to $\mathrm{AE}$ across regulatory types, equation (3) is estimated separately for the firms included in each regulation type. Table 3 reports the regression 
TABLE 3. Analyses of Price Responses to Positive and Negative Abnormal Profits for Utilities Subject to Different Regulatory Structures ( $t$-values Are in Parentheses).

\begin{tabular}{lccc}
\hline \multicolumn{4}{c}{$R_{i}=\alpha_{0}+\gamma_{1} A E_{i}+\gamma_{2}\left(D \times A E_{i}\right)+\gamma_{3}\left(C L M \times A E_{i}\right)$} \\
& \multicolumn{4}{c}{ Type I-Utilities } & Type II-utilities & Type III-utilities \\
\hline & .106 & .09 & .083 \\
$\alpha_{0}$ & $(1.25)$ & $(1.27)$ & $(1.05)$ \\
$\gamma_{1}$ & .535 & 1.124 & 2.283 \\
& $(2.51)^{* *}$ & $(2.96)^{* *}$ & $(3.66)^{* * *}$ \\
$\gamma_{2}$ & -.391 & -1.02 & -2.345 \\
& $(-2.91)^{* *}$ & $(-2.87)^{* *}$ & $(-3.24)^{* * *}$ \\
$\gamma_{3}$ & .403 & .349 & .874 \\
$\gamma_{4}$ & $(1.64)^{*}$ & $(1.84)^{*}$ & $(2.1)^{*}$ \\
& -1.177 & 1.365 & -2.168 \\
$\gamma_{5}$ & $(-2.61)^{* *}$ & $(2.59)^{* *}$ & $(-4.97)^{* * *}$ \\
& -1.858 & -1.556 & -2.002 \\
$R^{2}$ & $(-2.73)^{* *}$ & $(2.95)^{* * *}$ & $(-3.07)^{* * *}$ \\
No. of observations & .212 & .297 & .35 \\
\hline
\end{tabular}

Note: $R=\left(P_{t}-P_{t-1}\right) / P_{t-1}$, is annual return, where $P_{t}$ is the fiscal year-end closing price adjusted for stock splits; $A E_{t}=B_{t} \times A E_{t}=B_{t} \times\left(A P R_{t}-M P R_{t}\right) / P_{t-1}$; where $B_{t}$ is the book value per share and $A P R$ and $M P R$ are the actual and maximum allowed rates of return, respectively; $D=$ profit indicator that is 1 if $A P R>M P R$ and 0 otherwise; $C L M=$ climate indicator that is 1 if a firm is in a favorable regulatory climate and 0 otherwise; and $S Z=$ size indicator that is 1 if firm size is greater than the median size for all utilities in the sample and 0 otherwise. *Significant at .05 probability; **Significant at .01 probability; ***Significant at .001 probability.

results for the firms under type-I, type-II, and type-III regulations.

The coefficient for positive AE, $\gamma_{1}$, is $.535,1.124$, and 2.283 for type-I, type-II, and type-III utilities, respectively. The t-value for each coefficient is significant $(P<.05)$. These results show that, on average, positive AE have positive effects on returns, consistent with hypothesis 1. The marginal effect of negative AE on returns, $\gamma_{2}$, is negative and significant $(\mathrm{P}<.05)$ across the three regulation types, demonstrating asymmetry in return responses to positive and negative AE. The response coefficient for negative AE, $\left(\gamma_{1}+\gamma_{2}\right)$, is .144 for type-I utilities, .104 for type-II utilities, and -.062 for type-III utilities. The signs and 
sizes of these coefficients suggest that return responses to negative AE are most favorable for type-III utilities. However, the estimated t-values for the coefficients are 1.22, .101, and, 1.05 respectively, and thus insignificant at conventional probability levels. ${ }^{23}$ Consistent with hypothesis 2 , return responses to negative $\mathrm{AE}$ are not significant and are smaller than the return responses to positive AE. The insignificant return responses to negative $\mathrm{AE}$ are, perhaps, related to the various orders of regulation that provide opportunities for utilities to defer and subsequently recoup abnormal declines in profits. As predicted, the coefficient, $\gamma_{5}$, is negative and significant $(P<.01)$ across the three regulation types, providing further evidence that the return response is decreasing in the absolute value of AE.

\section{The Mediating Effects of Regulatory Climate and Firm Size}

The regulatory-climate coefficient, $\gamma_{3}$, is $.403, .349$, and .874 for type-I, type-II, and type-III utilities, respectively. These results are consistent with the proposition that the ability of utilities to earn and sustain positive changes in profits is increasing in the favorableness of regulatory climate. Utilities in favorable (unfavorable) climates are perceived to be under loose (restrictive) profit-recovery rules and are subject to policies that are favorable (unfavorable) to stockholders. Accordingly, a positive change in profits may persist for a longer (shorter) period for utilities in favorable (unfavorable) climates, leading to the observed effects on returns.

The effect of firm size on the association between returns and $\mathrm{AE}$ is positive for type-II utilities, whereas it is negative for type-I and typeIII utilities. The result for type-II utilities is consistent with the view that the ability to achieve cost savings through efficient fuel use is increasing in size. One potential explanation for such a scenario is that large utilities possess superior resources that allow them to obtain scale economies in fuel procurement and use. The large negative size-effect for type-III utilities is striking. This result, perhaps, reflects the structure of type-III programs that focus largely on long-run cost savings through improvements in capacity factors. Under such a structure, capacity increases and any resultant $\mathrm{AE}$ may be particularly vulnerable to regulatory penalty (e.g., disallowance of costs of extra capacity from the

23. The test statistic is computed as: $t\left(\gamma_{j, 2}+\gamma_{j, 3}\right)=\left(\gamma_{j, 2}+\gamma_{j, 3}\right)\left[\sigma^{2}\left(\gamma_{j, 2}\right)+\sigma^{2}\left(\gamma_{j, 3}\right)-2 \operatorname{Cov}\left(\gamma_{j, 2}, \gamma_{j, 3}\right)\right]^{-1 / 2}$ 
rate base), leading to the observed negative effects of firm size on the association between returns and $\mathrm{AE}$.

\section{Tests of Equality of Coefficients Across Regulation Types}

Hypothesis 3, in part, posits that return responses to positive $\mathrm{AE}$ are larger for IR utilities than for TRR utilities. The hypothesis of interest corresponds to the restrictions that $\left(\gamma_{12}-\gamma_{11}\right)>0$ and $\left(\gamma_{13}-\gamma_{11}\right)>0$, or, equivalently, that the effect of positive $\mathrm{AE}$ on returns is larger for IR than for TRR utilities. The analyses rely on $t$-values estimated as: $t\left(\gamma_{1, j}>\gamma_{1, i}\right)=\left(\gamma_{1, j}-\gamma_{1, i}\right)\left[\sigma^{2}\left(\gamma_{1, j}\right)+\sigma^{2}\left(\gamma_{1, i}\right)\right]^{-1 / 2}$. The estimate $t$-values are 1.52 and 2.7. Both test statistics are significant at the .05 probability level. This implies that return responses to positive $\mathrm{AE}$ are not equal across regulation types. Consistent with hypothesis 3 , return responses to positive AE are larger and more favorable for IR utilities than for TRR utilities. The other aspect of hypothesis 3 relates to the variation in the marginal effect of negative $\mathrm{AE}$ on returns across regulation types. The hypothesis of interest implies the restrictions that $\left(\gamma_{2,2}-\gamma_{2,1}\right)<0$ and that $\left(\gamma_{2,3}-\gamma_{2,1}\right)<0$, or, equivalently, that the marginal effect of negative AE on returns is less adverse for IR than for TRR utilities. The estimate $t$ values are -2.18 and -2.65 . Both test statistics are also significant at .05 probability level. Thus, the incremental effects of negative AE on annual returns are not equal across regulation types. The test results imply that the effect of negative AE on annual returns is less adverse (more favorable) for IR utilities than for TRR utilities, providing additional support for hypothesis 3 .

\section{E. Tests of Equality of Coefficients between Type-III and Type-II Utilities}

The first aspect of hypothesis 4 focuses on the variation of return responses to positive $\mathrm{AE}$ between type-II and type-III utilities. The specific hypothesis focuses on the restriction that $\left(\gamma_{1,3}-\gamma_{1,2}\right)>0$. The estimated $t$-value is 1.64 and significant $(P<.05)$. Consistent with hypothesis 4 , return responses to positive $\mathrm{AE}$ are larger and more favorable for type-III utilities than for type-II utilities. The second aspect of hypothesis 4 relates to the equality of the marginal effect of negative AE on returns for type-II and type-III utilities. The hypothesis of interest focuses on the restriction that $\left(\gamma_{2,3}-\gamma_{2,2}\right)<0$. The estimated $t$ - 
value is -.623 and not significant. This test provides little evidence that return responses to negative $\mathrm{AE}$ are less adverse (more favorable) for type-III than for type-II utilities. Based on this finding, one can plausibly infer that the recovery prospects for abnormal declines in profits are relatively similar under the various incentive regimes.

\section{F. Test of Equality of Regulatory-Climate and Firm-Size Effects} Across Regulation Types

The proposition that the mediating effects of regulatory climate on the association between returns and AE are identical for IR and TRR utilities tests the restrictions that $\left(\gamma_{3,2}-\gamma_{3,1}\right)>0$ and $\left(\gamma_{3,3}-\gamma_{3,1}\right)>0$. The corresponding $t$-values are -.17 and .97 . Both test statistics are not significant at the conventional .05 probability level. Furthermore, the test-statistic, $t\left(\gamma_{3,3}-\gamma_{3,2}\right)$, is 1.15 and not statistically significant. Thus, we cannot reject the proposition that the effects of regulatory climate on the association between returns and $\mathrm{AE}$ are equal across the three regulation types. The proposition that the size effects are equal for incentiveregulated and traditional rate-of-return utilities corresponds to the restrictions that $\left(\gamma_{4,2}-\gamma_{4,1}\right)>0$ and $\left(\gamma_{4,3}-\gamma_{4,1}\right)>0$. The test statistic, $t\left(\gamma_{4,2}-\gamma_{4,1}\right)$, is 3.66 and significant $(P<.05)$. The test statistic, $t\left(\gamma_{4,2}-\gamma_{4,1}\right)$, is -1.04 and not significant. Furthermore, the test-statistic, $t\left(\gamma_{4,3}-\gamma_{4,1}\right)$, is -4.02 and significant $(\mathrm{P}<.05)$. These finding suggest that there is a greater positive association between returns and $\mathrm{AE}$ for type II-utilities than for type-I and type-III utilities. Large utilities under type-III regulation have the most negative effect on the association between returns and $\mathrm{AE}$.

\section{G. Robustness Check}

To examine the robustness of the preceding results across an alternative design, all of the observations are pooled across regulation types and each panel is separately identified using an indicator variable. The pooled regression model is shown below:

$$
\begin{gathered}
=\alpha_{0}+\alpha_{0, I I}+\alpha_{0, I I I}+\gamma_{1} A E_{t}+\gamma_{1,2}\left(D_{I I} \times A E_{t}\right) \\
+\gamma_{1,3}\left(D_{I I I} \times A E_{t}\right)+\gamma_{2}\left(D_{t} \times A E_{t}\right)+\gamma_{2,2}\left(D_{t} \times D_{I I} \times A E_{t}\right)
\end{gathered}
$$




$$
\begin{aligned}
& +\gamma_{2,3}\left(D_{t} \times D_{I I I} \times A E_{t}\right)+\gamma_{3}\left(C L M \times A E_{t}\right) \\
& +\gamma_{4}\left(S Z \times A E_{t}\right)+\gamma_{5}\left(A E_{t}^{2}\right)+e_{t}
\end{aligned}
$$

The rest of the variables are as previously defined in equation 3 .

The preceding design benefits from improved sample size and permits comparisons of coefficients using the full covariance structure. The results (not separately reported for brevity) yield conclusions similar to the results based on the analysis of separate panels. In particular, the estimated value ( $t$-value) of $\gamma_{1}$ is .627 (2.77) and the estimated values ( $t$-values) of $\gamma_{1,2}$ and $\gamma_{1,3}$ are .733 (2.04) and 1.206 (4.22), respectively. The value ( $t$-value) of $\gamma_{2}$ is $-.231(-2.18)$; the estimated values ( $t$-values) of $\gamma_{2,2}$ and $\gamma_{2,3}$ are -1.097 (2.72) and -1.805 (3.84), respectively. The intercept dummies are not significantly different from zero. These results are consistent with the predictions that the absolute size of returns associated with negative $\mathrm{AE}$ is significantly less than the absolute size of returns associated with positive AE for utilities. Moreover, these latter results confirm the results of the preceding section that AEs (positive and negative) have larger and more favorable effects on returns for incentive-regulated utilities than for traditional utilities.

\section{Summary and Concluding Remarks}

This article has examined how rate-of-return regulation and variations in the structure of regulation affect return responses to positive and negative abnormal earnings. The results show that return responses to positive and negative abnormal earnings are asymmetric. Specifically, 
the absolute size of return responses are larger for positive than for negative abnormal earnings. There is also marked variation in return responses across regulatory structures. Specifically, return responses to abnormal earnings are more favorable for incentive-regulated utilities than for traditional rate-of-return utilities. For the incentive-regulated utilities, return responses to positive abnormal earnings are more favorable for firms whose incentive programs target generating plants and long-term cost savings than for firms whose incentive programs focus on fuel costs and/or short-term cost savings. Moreover, regulatory climate has a positive effect on the association between returns and abnormal earnings. The firm-size effect is mixed. For utilities subject to incentive programs that focus on short-term cost savings, utility size has a positive effect on the association between returns and abnormal earnings. For other utilities, the effect is negative.

The pricing results support the contention that existing regulatory structures confer different information contents to positive and negative abnormal earnings. In particular, the market interprets abnormal earnings more favorably for utilities subject to incentive regulation compared to those utilities under the traditional rate-of-return regulation. The implication is that superior earnings performance has more value-relevant information for incentive-regulated utilities than for traditional rate-ofreturn utilities. From a policy standpoint, the finding can be interpreted as evidence that loosening the profit constraints on regulated utilities provides incentive for performance improvements that have economic implications. These findings are inconsistent with a pure cost-plus pricing and perhaps point to the ineffectiveness of regulation in continuously matching revenues with the cost of rendering services. Alternatively, the results may portend a complex set of investor reactions to earnings news that are conditioned by factors such as the sign of the earnings news and the regulatory climate governing the earnings process. The results also have implications for empirical research. The finding of asymmetric return responses to positive and negative AE suggests that explicit consideration of the sign of earnings signals may improve empirical specification of the returns-earnings relation.

\section{References}

Abdel-khalik, R. A. 1988. Incentives for accruing costs and efficiency in regulated monopolies subject to ROE constraint. Journal of Accounting 
Research 26 (Supplement): 144-174.

APB. 1962. APB Opinion No. 2: Accounting for the Investment Credit. New York, NY.: AICPA.

Archer, S. H. 1981. The regulatory effects on cost of capital in electric utilities. Public Utilities Fortnightly (February): 36-39.

Atiase, R. K. 1985. Pre-disclosure information, firm capitalization, and security price behavior around earnings announcements. Journal of Accounting Research 23 (Spring): 21-36.

Bailey, E. E. and Coleman, R. D. 1971. The effect of lagged regulation in an Averch-Johnson model. The Bell Journal of Economics and Management Science 2 (Spring): 278-292.

Banz, R. W. 1981. The relationship between return and market value of common stocks. Journal of Financial Economics 9 (March): 3-18.

Baron, D. P. and De Bondt, R. R. 1981. On the design of regulatory price adjustment mechanism. Journal of Economic Theory 24 (February): 70-94.

Basu, S. 1997. The conservatism principle and the asymmetric timeliness of earnings. Journal of Accounting and Economics 24 (December): 3-37.

Baumol, W. J. 1968. Reasonable rules for rate regulation: plausible policies for an imperfect world. In prices: Issues in theory, practice, and public policy, edited by A. Phillips, and O. E. Williamson. Philadelphia: University of Pennsylvania Press.

Beaver, W.; Lambert, R.; and Ryan, S. 1987. The information content of security prices: A second look. Journal of Accounting and Economics 9 (July): 139 - 157.

Brooks, L. D. and Buckmaster, D. A. 1976. Further evidence of the time-series properties of accounting income. Journal of Finance 31 (December): 13591373.

Bryan, S. and Hwang, L. 1997. CEO compensation in a regulated environment: An analysis of the utility industry. Journal of Accounting, Auditing, and Finance 12 (Summer): 223 - 251

Carleton, W. T. 1974. Rate of return, rate base, and regulatory lag under conditions of changing capital costs. Land Economics 50 (May): 145-151.

Cheng, C. S. A.; Hopwood, W. S.; and McKeown, J. C. 1992. Non-linearity and specification problems in unexpected earnings response regression model. The Accounting Review 67 (July): 579 - 589.

Clarke, R. G. 1980. The effect of fuel adjustment clauses on the systematic risks and market value of electric utilities. Journal of Finance 35 (May): 347-358.

Das, S. and Lev, B. 1994. Non-linearity in the returns-earnings relation: Tests of alternative specifications and explanations. Contemporary Accounting Research 11 (Fall): 353-380.

Edison Electric Institute. 1987. Incentive Regulation in the Electric Utility 
Industry, Washington, D. C.: Edison Electric Institute.

Elsharkawy, A. and Garrod, N. 1996. The impact of investor sophistication on price responses to earnings news. Journal of Business Finance and Accounting 23 (March): 221-236.

Elsgers, P. T. and Lo, M. H. 1994. Reduction in analysts' annual earnings forecast errors using information in prior earnings and security returns. Journal of Accounting Research 32 (Autumn): 290-303.

FASB. 1982. Statement of Financial Accounting Standards No. 71: Accounting for the Effects of Certain Types of Regulation. Stamford, CT.: FASB.

FASB. 1988. Statement of Financial Accounting Standards No. 101: Regulated Enterprises-Accounting for the Discontinuation of FASB Statement No. 71. Stamford, CT.: FASB.

FASB. 1995. Statement of Financial Accounting Standards No. 121: Accounting for the Impairment of Long-Lived Assets and for Long-Lived Assets to Be Disposed Of. Stamford, CT.: FASB.

Freeman, R. N. 1987. The association between accounting earnings and security returns for large and small firms. Journal of Accounting and Economics 9 (July):195-228.

Hagerman, R. L. and Ratchford, B. T. 1978. Some determinants of allowed rates of return on equity to electric utilities. The Bell Journal of Economics 9 (Spring): 46-55.

Hayn, C. 1995. The information content of losses. Journal of Accounting and Economics 20 (September): 125-153.

Joskow, P. L. 1973. Pricing decisions of regulated firms: A behavioral approach. The Bell Journal of Economics 4 (Spring): 118-140.

Joskow, P. L. 1974. Inflation and environmental concerns: Structural change in the process of public utility price regulation. Journal of Law and Economics 17 (October): 1-16.

Joskow, P. L. and MacAvoy, P. W. 1975. Regulation and the financial condition of the electric power companies in the 1970's. The American Economic Review 65 (May): 295-301.

Joskow, P. L. and Schmalensee, R. 1986. Incentive regulation for electric utilities. Yale Journal of Regulation 4 (Fall): 1-50.

Khurana, I. K. and Loudder, M. L. 1994. The economic consequences of SFAS No. 106 in rate regulated industries. The Accounting Review 69 (April): 364-380.

Lanen, N. W. 1996. Incentive regulation programs and electric utility performance. Working Paper: University of Michigan, Ann Arbor, MI.

Landon, J. 1990. Incentive Regulation in the Electric Utility Industry. National Economic Research Associates, San Francisco, CA.

Loudder, M. L.; Khurana, I. K.; and Boatsman, J. R. 1996. Market valuation of regulatory assets in public utility firms. The Accounting Review 3 (July): 
357-373.

Manzi, J. E. 1986. When a utility faces disallowances of new plant investment. Public Utilities Fortnightly (March): 39-43.

Norton, S. 1985. Regulation and systematic risk: The case of electric utilities. Journal of Law and Economics 28 (October): 671 - 686.

Nwaeze, E. T. 1997a. Rate-of-return regulation and the behavior of the return on equity for electric utilities. Journal of Economics and Business 49 (September/October): 491-510.

Nwaeze, E. T. 1997b. Incentive regulation, investment decisions, and stock returns. Journal of Accounting, Auditing, and Finance 12 (Fall): 391-414.

Penno, M. 1996. Unobservable precision choices in financial reporting. Journal of Accounting Research 34 (Spring): 141 - 149.

Philbrick, D. R. and Ricks, W. E. 1991. Using Value Line and IBES analyst forecasts in accounting research. Journal of Accounting Research 29 (Autumn): 397 - 417.

Rao, R. and Moyer, R. Charles. 1994. Regulatory climate and electric utility capital structure decisions. The Financial Review 29 (February): 97-124.

Reinganum, M. R. 1981. Misspecification of capital asset pricing: empirical anomalies based on earnings yield and market value. Journal of Financial Economics 9 (March): 19-46.

Sappington, D. 1980. Strategic firm behavior under a dynamic regulatory adjustment process. The Bell Journal of Economics 11 (Spring): 360-372.

Sherman, R. 1989. The Regulation of Monopoly. New York: Cambridge University Press.

Smarrt, L. E. 1986. A state ruling unravels utility regulation a little further. Public Utilities Fortnightly (February): 4-6.

Stober, T. 1988. Discussion of incentives for accruing costs and efficiency in regulated monopolies subject to Roe constraint. Journal of Accounting Research 26 (Supplement):175-181.

Subramanyam, K. R. 1996. Uncertain precision and price reactions to information. The Accounting Review 71 (April): 207 - 220 